\title{
WKY, Rat Strain
}

National Cancer Institute

\section{Source}

National Cancer Institute. WKY, Rat Strain. NCI Thesaurus. Code C76192.

An outbred Wistar substrain derived at Kyoto school of medicine and disseminated to the NIH in 1971 and finally to Charles River in 1974. The Wistar Kyoto is a white albino with pink eyes, genotype c. This rat strain is used in cardiac and behavioral research and as a control for studies involving the spontaneous hypertensive rat. 